\title{
Experimental Verification of Theoretical Configuration Mixing in the Energy Levels of Er II Spectra via Isotope Shift Measurements Using a FTS
}

\author{
Balkrishna Keraba Ankush, ${ }^{1,}$, Mukul Narayan Deo ${ }^{2}$ \\ ${ }^{1}$ Atomic and Molecular Physics Division, Bhabha Atomic Research Centre, Trombay, Mumbai, India \\ ${ }^{2}$ High Pressure and Synchrotron Radiation Physics Division, Bhabha Atomic Research Centre, Trombay, Mumbai, India
}

Email address:

bkankush@barc.gov.in (B. K. Ankush)

*Corresponding author

\section{To cite this article:}

Balkrishna Keraba Ankush, Mukul Narayan Deo. Experimental Verification of Theoretical Configuration Mixing in the Energy Levels of Er II Spectra via Isotope Shift Measurements Using a FTS. American Journal of Astronomy and Astrophysics. Vol. 5, No. 2, 2017, pp. 10-20. doi: 10.11648/j.ajaa.20170502.11

Received: February 8, 2017; Accepted: February 22, 2017; Published: March 9, 2017

\begin{abstract}
We report the first detailed investigation on isotope shift, $\Delta \sigma^{166,170}$ measurements carried out in the spectrum of singly- ionized erbium (Er II/ $\mathrm{Er}^{+}$) recorded with a FTS. Isotope shift in 85 spectral lines were determined in the $350-590 \mathrm{~nm}$ wavelength region. The source was accomplished of mixture of highly enriched isotopes of ${ }^{166} \mathrm{Er}:{ }^{170} \mathrm{Er}$ in $7: 10$ ratio respectively and the detector was a photomultiplier tube. These investigations have contributed significantly to the understanding of the 92 known energy levels of $\mathrm{Er}^{+}$. Level isotope shift, $\Delta \mathrm{T}^{166,170}$ values have been evaluated for 29 even- and 63 odd- parity energy levels for the first time. On the basis of the derived level isotope shifts the configuration mixing was estimated for altogether 92 involved levels and compared those with the theoretically predicted configuration mixings available in the literature and found that both the theoretical and experimental mixings have excellent agreement with each other.
\end{abstract}

Keywords: Isotope Shift, Configuration Mixing, Singly-Ionized Spectra, Fourier Transform Spectrometer, Hollow Cathode Lamp

\section{Introduction}

The comprehensive list of the energy levels of the singly ionized erbium atom (Er II)was published by Martin et al. [1] taking aid from the unpublished extension of the Er II spectral analysis carried out by van Kleef TAM et al.[2]. Sugar et al. [3] have derived the ionization potential $11.93 \mathrm{eV}$ $( \pm 0.08 \mathrm{eV})$ of $\mathrm{Er}^{+}$along with the other rare earth ions i.e. from $\mathrm{La}$ II to $\mathrm{Lu}$ II by means of semi empirical calculations. The analysis of lifetimes of 11 odd- parity levels and measurement of precise transition energies for several spectral lines of Er II were conducted in the reference [4]. Improved values of laboratory transition probabilities for 418 lines of Er II were presented and employed those values for the Er abundance measurement of the sun and five r- processrich metal-poor stars [5]. Wyart et al. [6] have classified and extended both theoretically and experimentally the Er II spectra to interpret the known energy levels first parametrically using Cowan code and then the predictions of the unknown energy levels employed for the classification of the experimental hollow cathode FT spectra. Their detailed investigation of level configurations has shown that the levels of $4 \mathrm{f}^{12} 6 \mathrm{p}$ were strongly mixed with $4 \mathrm{f}^{11} 5 \mathrm{~d} 6 \mathrm{~s}$ and $4 \mathrm{f}^{11} 5 \mathrm{~d}^{2}$ configurations and provided the configuration mixing in percentages for most of the known even and odd levels. The hyperfine structure for $4 \mathrm{f}^{12} 6 \mathrm{~s}$ and $4 \mathrm{f}^{12} 5 \mathrm{~d}$ configurations of ${ }^{167} \mathrm{Er}$ in 14 transitions of Er II were carried out with the collinear fast-beam laser and radio-frequency laser doubleresonance spectroscopy techniques and reported the hfs Aand B- coupling constants of various Er II levels for the ${ }^{167} \mathrm{Er}$ isotope [7]. Isotope shift (IS) data in the spectral lines of Er II was very scarce in the literature. Wilets and Bradley [8] have reported IS in 67 spectral lines of Er and they argued that most of these lines belong to Er II spectrum. However only 6 of these lines falling at $4552.13 \AA, 4820.75 \AA, 5164.77 \AA$, $5485.93 \AA, 6006.80 \AA$ and $6076.44 \AA$ were classified as Er II 
lines in NBS Tables [9]; and the remaining 61 lines belong to Er I spectrum as have claimed by [10]. Determination of the intrinsic quadrupole moment of ${ }^{162} \mathrm{Er}$ was carried out in [11] using the IS data of the Er I and Er II lines. Pacheva et al. [12] have published only abstract where no details are given of the Er II lines in which they conducted IS measurements. IS in 9 lines along with the crossed-second-order effects of the IS in the ground configuration $4 \mathrm{f}^{12} 6 \mathrm{~s}$ of Er II were measured [13] using enriched isotopes of ${ }^{166} \mathrm{Er}$ and ${ }^{170} \mathrm{Er}$ and computer- interfaced Fabry- Perot Spectrometer.

The objectives of the present investigation were to obtain the IS data in as many spectral lines of Er II as possible in the first stage because so far IS data in only 9 lines have been reported earlier [13] and in the second stage to evaluate the IS of even- and odd- parity energy levels and use this data to designate the configurations to the known but unassigned levels as all the even- levels between $38400-43400 \mathrm{~cm}^{-1}$ and the odd- levels above $21000 \mathrm{~cm}^{-1}$ have tentative configuration assignments and all the known 54 even levels above $43400 \mathrm{~cm}^{-1}$ and 144 odd levels between 33000- 45000 $\mathrm{cm}^{-1}$ have no configuration designations. The status of classification of these levels [1] has been summarized in Table 1. In the third stage compare the experimentally derived configuration mixing with the theoretically calculated configuration mixing available in the literature [6].

As can be seen from Table 1, about 50 percent of the known even- and 80 percent of the known odd- parity levels are without configuration assignments.

Table 1. Status of configuration assignment to the known energy levels of Er II [1].

\begin{tabular}{lll}
\hline Parity & Energy Levels & Configuration status [1] \\
\hline & 12 & $4 \mathrm{f}^{12} 6 \mathrm{~s}$ \\
& 23 & $4 \mathrm{f}^{12} 5 \mathrm{~d}$ \\
Even (117 known levels) & 9 & $4 \mathrm{f}^{11} 6 \mathrm{~s} 6 \mathrm{p}$ \\
& 8 & $4 \mathrm{f}^{11} 6 \mathrm{~s} 6 \mathrm{p} ?$ \\
& 11 & $4 \mathrm{f}^{11} 5 \mathrm{~d} 6 \mathrm{p} ?$ \\
& 54 & Unassigned \\
& 3 & $4 \mathrm{f}^{11} 6 \mathrm{~s}^{2}$ \\
Odd (243 known levels) & 28 & $4 \mathrm{f}^{11} 5 \mathrm{~d} 6 \mathrm{~s}$ \\
& 2 & $4 \mathrm{f}^{11} 5 \mathrm{~d} 6 \mathrm{~s}(?)$ \\
& 10 & $4 \mathrm{f}^{11} 5 \mathrm{~d}^{2}(?)$ \\
& 195 & $4 \mathrm{f}^{12} 6 \mathrm{p}(?)$ \\
\hline
\end{tabular}

\section{Experimental Techniques}

IS, $\Delta \sigma^{166,170}$ were measured in the 67 lines falling in the 350 $590 \mathrm{~nm}$ region of the Er II spectra with a Bomem DA8 Fourier Transform Spectrometer (FTS). The light detector was photo multiplier tube (PMT) and the source was liquid nitrogen cooled hollow cathode lamp (HCL). The source consisted of manmade mixture (7:10 ratio) of highly enriched isotopes ${ }^{166} \mathrm{Er}$ (96.3\%) and ${ }^{170} \operatorname{Er}(98.0 \%)$ respectively in the oxide form. The sample weighing about 12- $15 \mathrm{mg}$ was coated on the copper crucible as a thin layer of paste prepared using distilled water. The coated crucible was dried under the infrared lamp and later heated to red hot on the Bunsen flame before inserting it into the HCL. Ne was filled at 2.5 mbar as a buffer gas and the discharge was run at $45 \mathrm{~mA}$ DC between the anode and cucathode maintaining 2-3 mm gap. To get an acceptable signal to noise ratio, about 90 minute integration time ( $\sim 50$ scans coadded) was used to record the each set of data. The entrance aperture of the spectrometer adjusted to $\sim 1 \mathrm{~mm}$ to give rise to the resolution of $0.02 \mathrm{~cm}^{-1}$.

During the IS measurements we considered the different parameters like intensity, Full width at half maximum (FWHM), the center of gravity of each component. All IS data were converted to $\left(1.10^{-3} \mathrm{~cm}^{-1}=30 \mathrm{MHz}\right) \mathrm{MHz}$ from wavenumber $\left(\mathrm{cm}^{-1}\right)$ scale. Er spectra encompass the Ne I and $\mathrm{Ne}$ II lines (FWHM $4500 \mathrm{MHz}$ ) in addition to Er I and Er II. IS $\Delta \sigma^{166,170}$ data in 660 Er I spectral lines has been already published in [14] in 2015. Er II lines exhibit $2000 \mathrm{MHz}$ FWHM at $350 \mathrm{~nm}$ and $1500 \mathrm{MHz}$ at $590 \mathrm{~nm}$. The spectral positions were shifted to $+0.200 \mathrm{~cm}^{-1}$ towards shorter wavelength region and $-0.05 \mathrm{~cm}^{-1}$ shift observed towards the longer wavelength region. The accuracy of the IS measurements for all lines was $\left( \pm 0.003 \mathrm{~cm}^{-1}\right) \pm 90 \mathrm{MHz}$. IS was said to be positive if the peak representing heavier isotope, ${ }^{170} \mathrm{Er}$ appears on the higher frequency side and it was negative if it appears on the lower frequency side. The IS 0 $\mathrm{MHz}$ suggests that the peaks of both the isotopes ${ }^{166} \mathrm{Er}$ and ${ }^{170}$ Er overlap one above another.

\section{Results and Discussions}

IS, $\Delta \sigma^{166,170}(\mathrm{MHz})$ data measured in the 85 lines of Er II are listed in Table 2 . The magnitude of IS observed presently was in the range of -3842 to $+1400 \mathrm{MHz}$. As can be seen from Table 2, 54 transitions observed are from high odd- parity levels to low even- parity levels, whereas the 31 transitions observed are from high even- to low odd- parity levels. 20 lines have exhibited positive IS and 60 lines have indicated negative IS whereas the remaining 5 spectral lines have shown no or 0 IS. The wavelengths of the spectral lines studied presently, their intensities and their relevant energy level classifications, are taken from Meggers et al. [9] and are presented in the column 1 . The IS $\Delta \sigma^{166,170}(\mathrm{MHz})$ data of the lines studied were presented in the column 2 of the Table 2. IS in the chosen 7 spectral lines at $357.075 \mathrm{~nm}, 363.354$ $\mathrm{nm}, 369.265 \mathrm{~nm}, 371.239 \mathrm{~nm}, 372.952 \mathrm{~nm}, 390.631 \mathrm{~nm}$, and at $590.208 \mathrm{~nm}$ of Er II recorded on FTS were exhibited in Figs. 1-7 respectively. The magnitude of IS as seen in Figures 1 and 4 is measurably large whereas it is too small to measure directly in Figures 2, 3, 5, 6 and 7 and had been extracted using profiles of single isotopes. Energy level classification (33129- $5132 \mathrm{~cm}^{-1}$ ) listed by Meggers et al. [9] for the line at 357.075 was unfit (see Fig. 1) and conclusively rejected by Wyart et al. [6]. The IS value $-2910 \mathrm{MHz}$ presently measured in the line was not agreeing with the classification listed by Meggers et al. [9] hence we also support the rejection of the said classification. Wyart et al. [6] have provided energy level classifications for the three lines compiled as unclassified lines in [9] at $495.360 \mathrm{~nm}, 502.428 \mathrm{~nm}$ and at $521.826 \mathrm{~nm}$. The present IS data derived in these lines support the recent classifications (see Table 2) calculated by Wyart et al. [6]. 


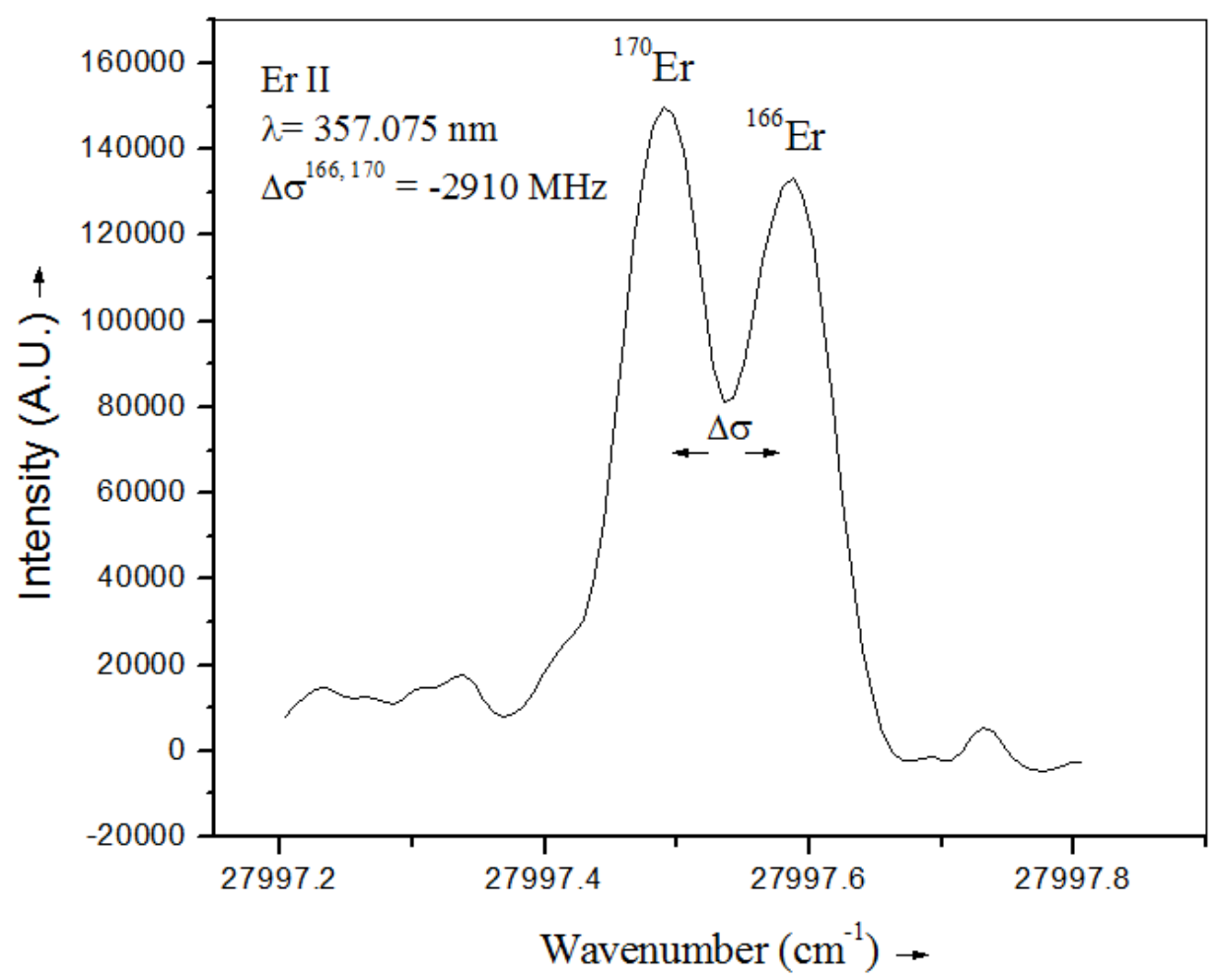

Figure 1. Er II FTS Spectrum, Wavelength, $\lambda=357.075 \mathrm{~nm}$ [Wavenumber, $\sigma=27997.304 \mathrm{~cm}^{-1}=33129.912 \mathrm{~cm}^{-1}(J=9 / 2) \Delta T^{166,170}(81 \mathrm{MHz})-5132.608 \mathrm{~cm}{ }^{-1}$ $\left.(J=9 / 2) 4 f^{2} 6 s \Delta T^{166,170}(2991 \mathrm{MHz})\right]$. This energy level classification compiled in Meggers et al. [9] was rejected by Wyart et al. [6]. The presently derived $\Delta T^{166,170}(81 \mathrm{MHz})$ for the level at $33129 \mathrm{~cm}^{-1}$ can not be classified under any of the odd configurations listed in the Table 3. Thus experimentally measured IS, $\Delta \sigma^{166,170}=-2910 \mathrm{MHz}$ data in this line does not suite with the existing classification [9] and supports its rejection. Light Source: Liquid nitrogen cooled HCL, Detector: PMT. a. u: Arbitrary units.

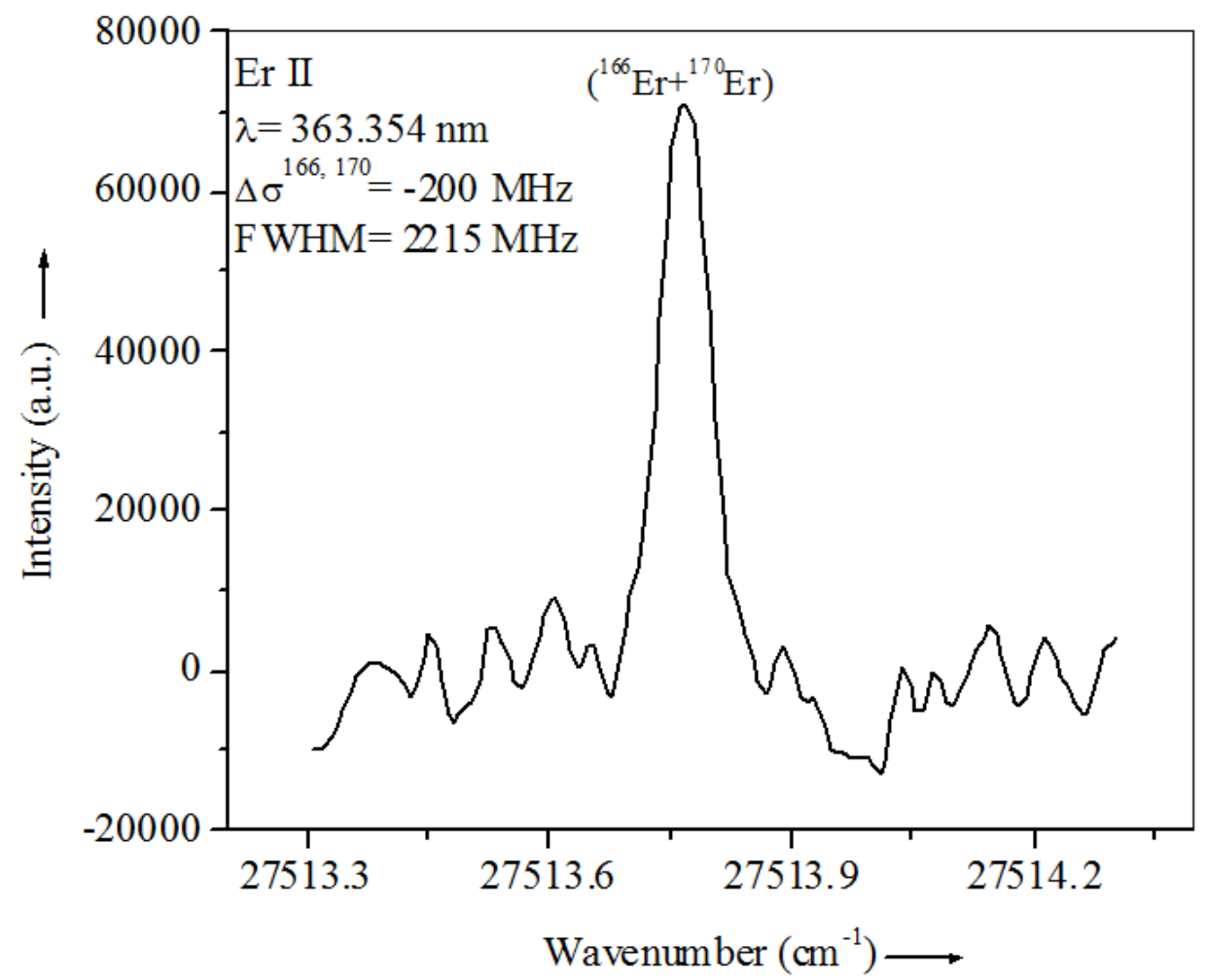

Figure 2. Er II FTS Spectrum, Wavelength, $\lambda=363.354 \mathrm{~nm}$ [Wavenumber, $\sigma=27513.555 \mathrm{~cm}^{-1}$, Energy Level Classification, $27513.555 \mathrm{~cm}^{-1}(J=13 / 2) \Delta T^{166}$ $\left.{ }_{170}(2798 \mathrm{MHz})-0.00 \mathrm{~cm}^{-1}(\mathrm{~J}=13 / 2) 4 f^{12} 6 s \Delta T^{166,170}(3000 \mathrm{MHz})\right]$. The extracted IS, $\Delta \sigma^{166,170}=-200 \mathrm{MHz}$, Light Source: Liquid nitrogen cooled HCL, Detector: PMT. 


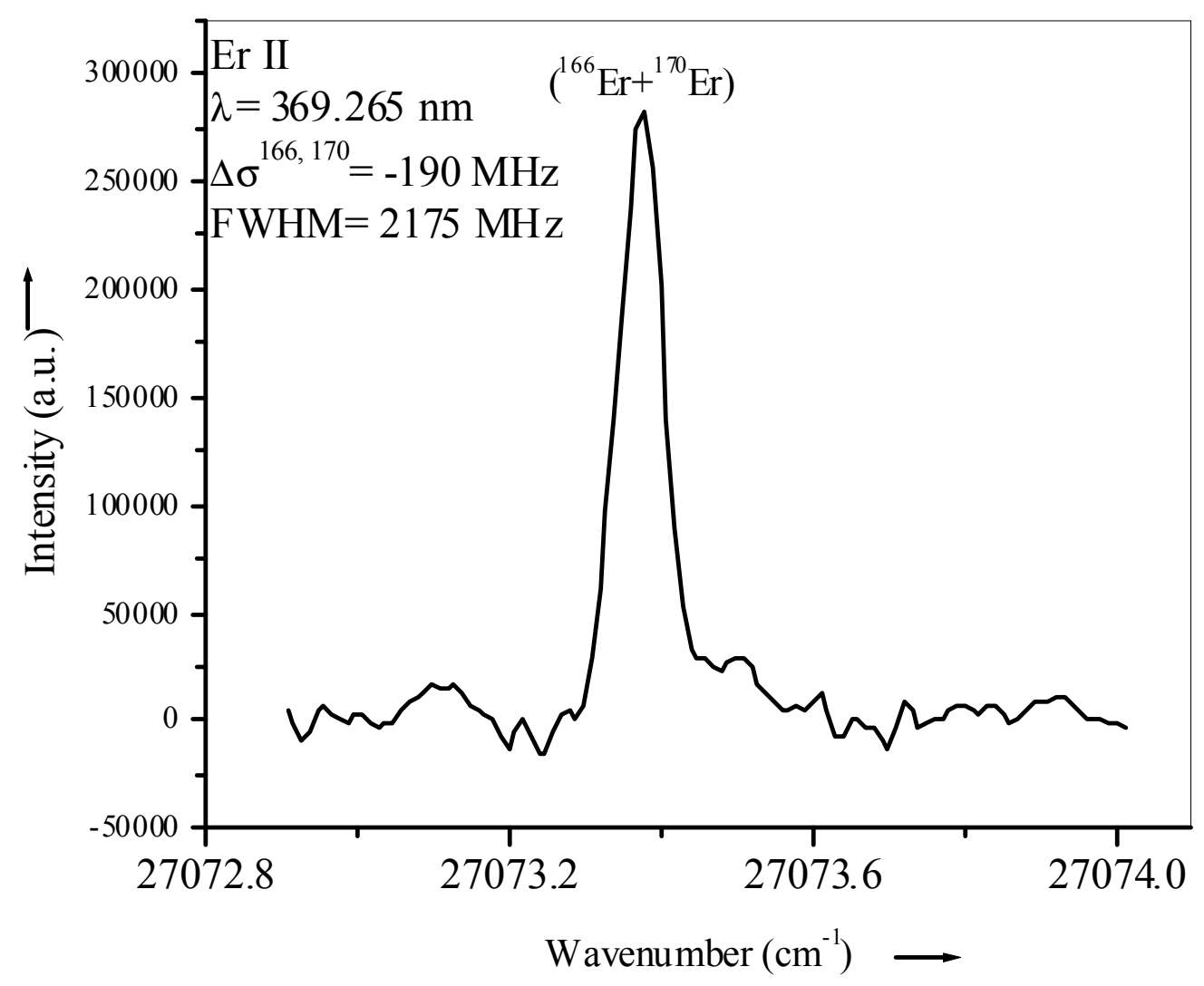

Figure 3. Er II FTS Spectrum, Wavelength, $\lambda=369.265 \mathrm{~nm}$ [Wavenumber, $\sigma=27073.11 \mathrm{~cm}^{-1}$, Energy Level Classification, $27513 \mathrm{~cm}^{-1}(J=13 / 2) \Delta T^{166,170}(2798$ $\left.M H z)-440 \mathrm{~cm}^{-1}(J=11 / 2) 4 f^{12} 6 s \Delta T^{166,170}(2990 \mathrm{MHz})\right]$. The extracted IS, $\Delta \sigma^{166,170}=-190 \mathrm{MHz}$, Light Source: Liquid nitrogen cooled HCL, Detector: PMT.

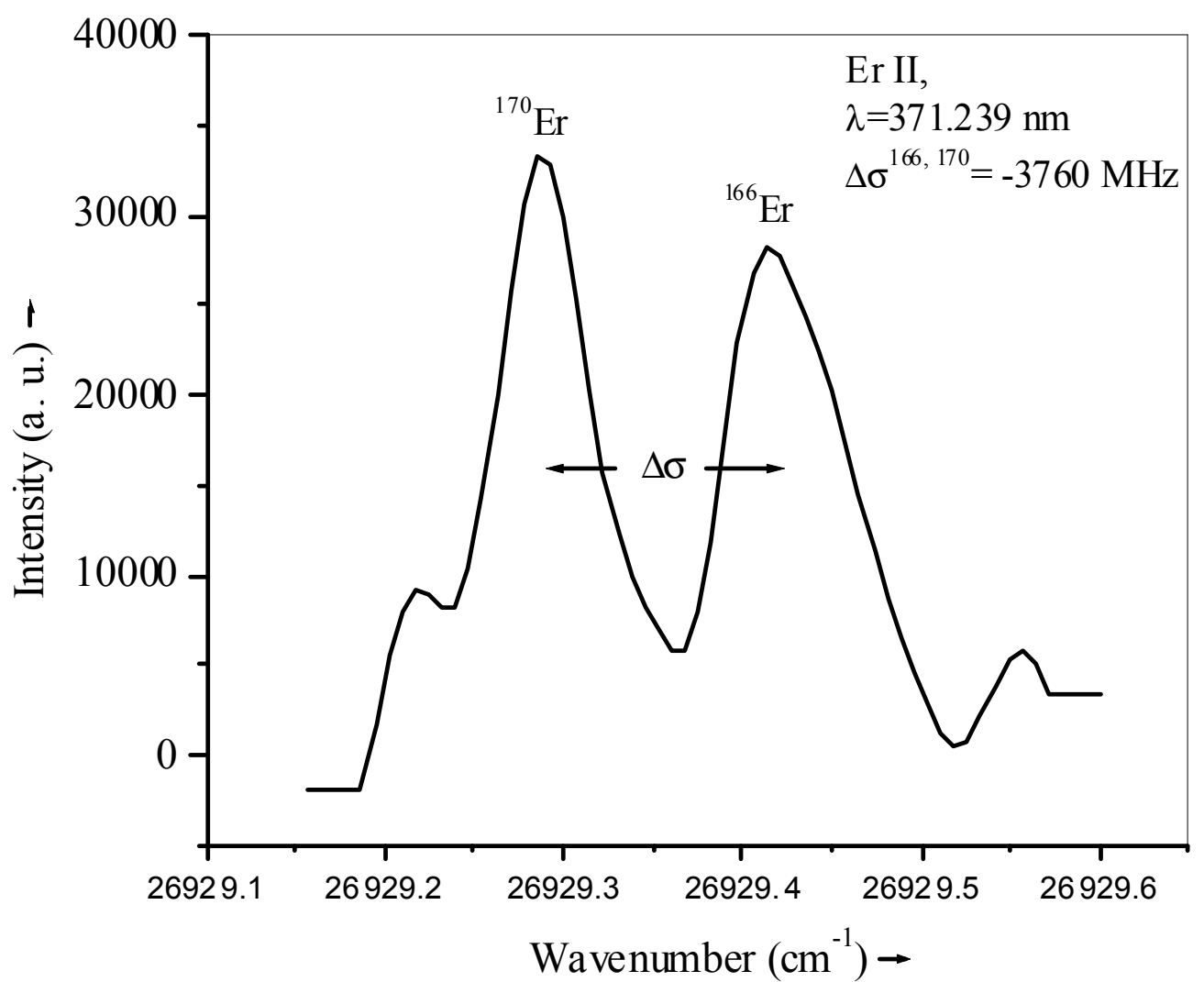

Figure 4. Er II FTS Spectrum, Wavelength, $\lambda=371.239 \mathrm{~nm}$ [Wavenumber, $\sigma=26929.246 \mathrm{~cm}^{-1}$, Energy Level Classification, $33753 \mathrm{~cm}^{-1}(\mathrm{~J}=13 / 2) \Delta T^{166}$ $\left.{ }^{170}(2671 \mathrm{MHz}) 4 f^{l 1} 6 s 6 p-6824 \mathrm{~cm}^{-1}(J=15 / 2) 4 f^{11} 6 s^{2} \Delta T^{166,170}(6430 \mathrm{MHz})\right]$. The experimentally measured IS, $\Delta \sigma^{166,170}=-3760 \mathrm{MHz}$. Light Source: Liquid nitrogen cooled HCL, Detector: PMT. 


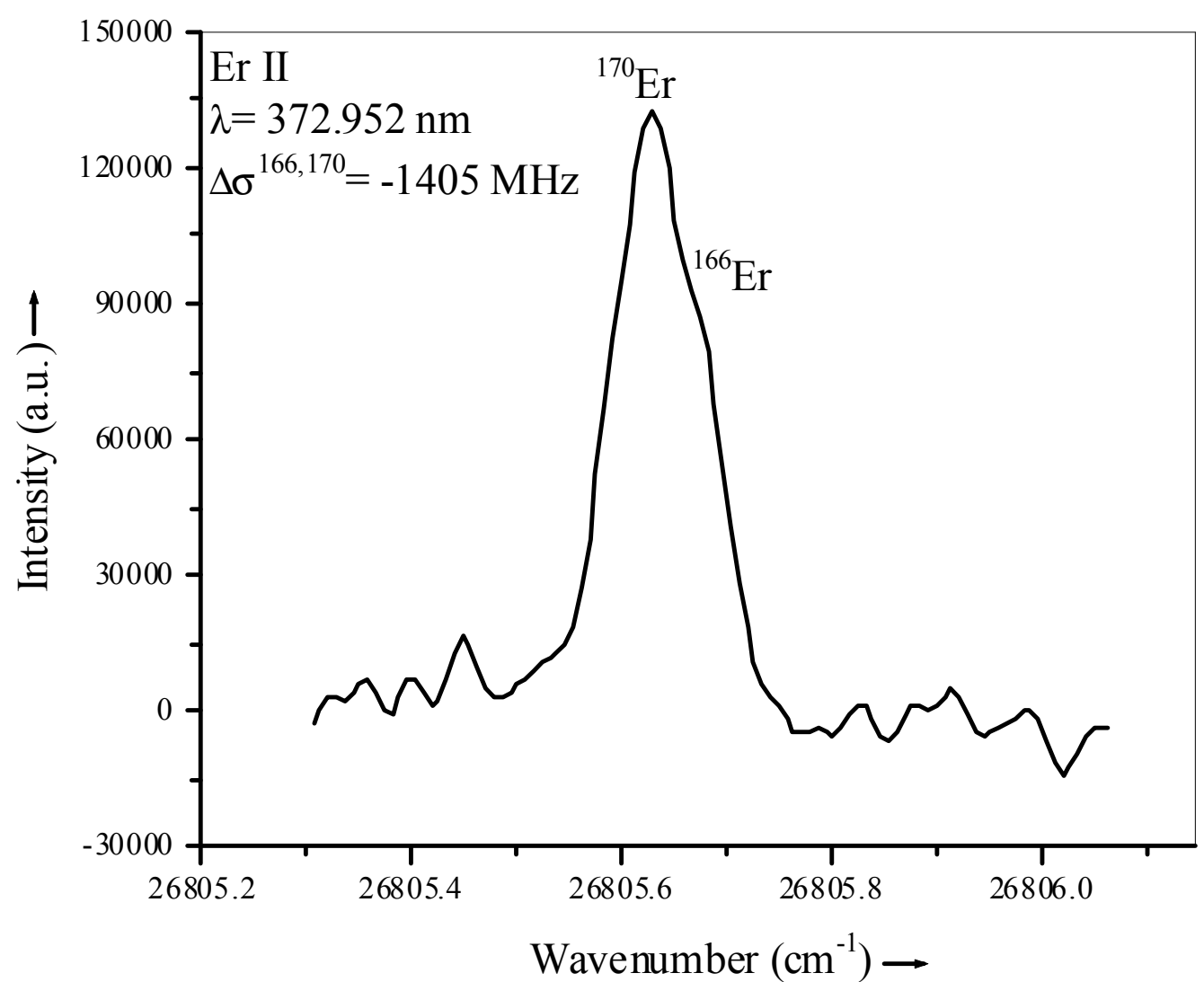

Figure 5. Er II FTS Spectrum, Wavelength, $\lambda=372.952 \mathrm{~nm}$ [Wavenumber, $\sigma=26805 \mathrm{~cm}^{-1}$, Energy Level Classification, $26805 \mathrm{~cm}^{-1}(J=11 / 2) \Delta T^{166,170}(1595$ $\left.M H z)-0.00 \mathrm{~cm}^{-1}(J=13 / 2) 4 f^{2} 6 s \Delta T^{166,170}(3000 \mathrm{MHz})\right]$. The extracted IS, $\Delta \sigma^{166,170}=-1405 \mathrm{MHz}$. Light Source: Liquid nitrogen cooled HCL, Detector: PMT.

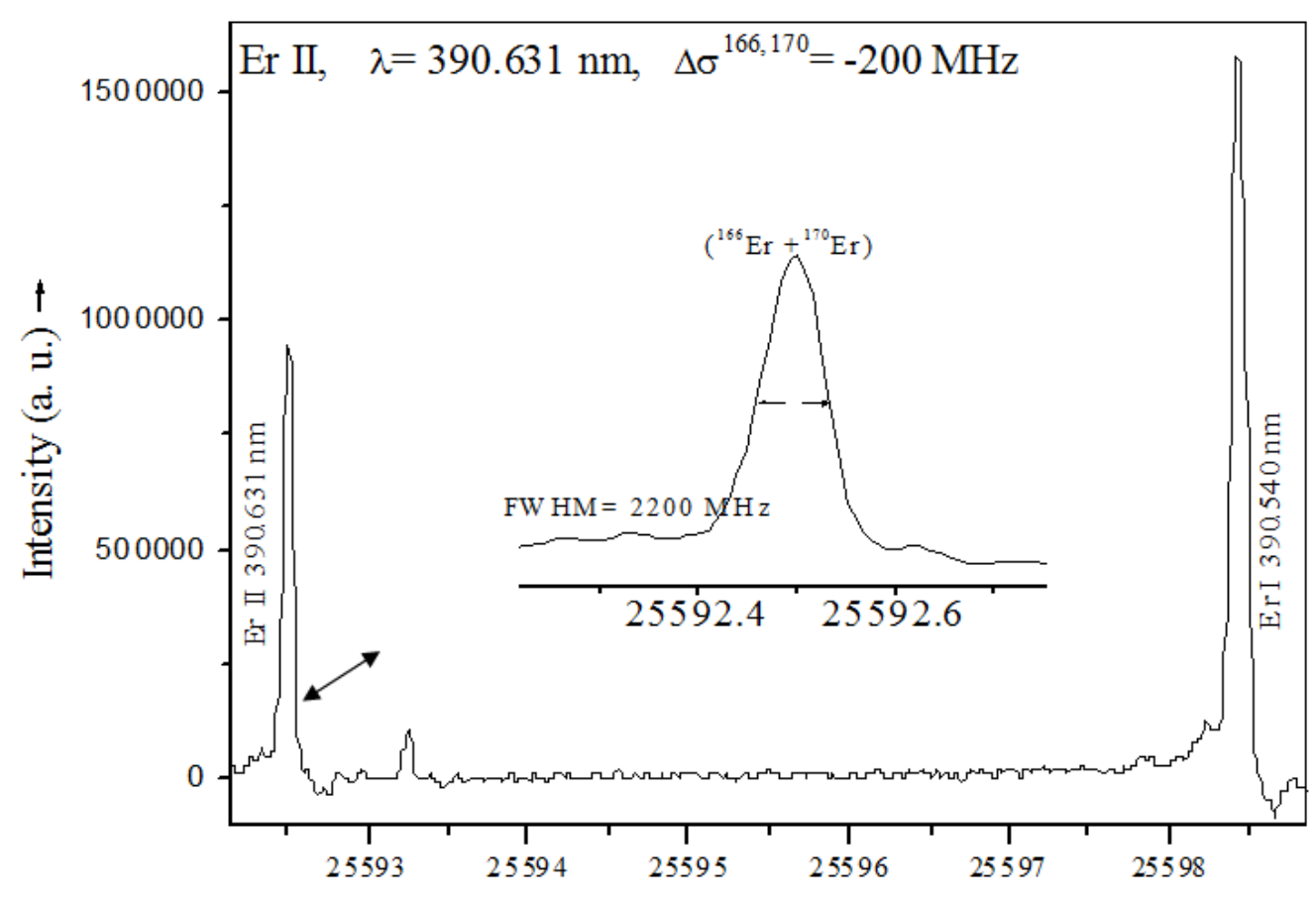

Wavenumber $\left(\mathrm{cm}^{-1}\right) \longrightarrow$

Figure 6. Er II FTS Spectrum, Wavelength, $\lambda=390.631 \mathrm{~nm}$ [Wavenumber, $\sigma=25592.343 \mathrm{~cm}^{-1}$, energy level classification $25592 \mathrm{~cm}^{-1}(J=11 / 2) 4 f^{12} 6 p, \Delta T^{166,170}$ $\left.(2798 \mathrm{MHz})-0.00 \mathrm{~cm}^{-1}(J=13 / 2) 4 f^{2} 6 s \Delta T^{166,170}(3000 \mathrm{MHz})\right]$. The extracted IS, $\Delta \sigma^{166,170}=-200 \mathrm{MHz}$. Light Source: Liquid nitrogen cooled HCL, Detector: PMT. 


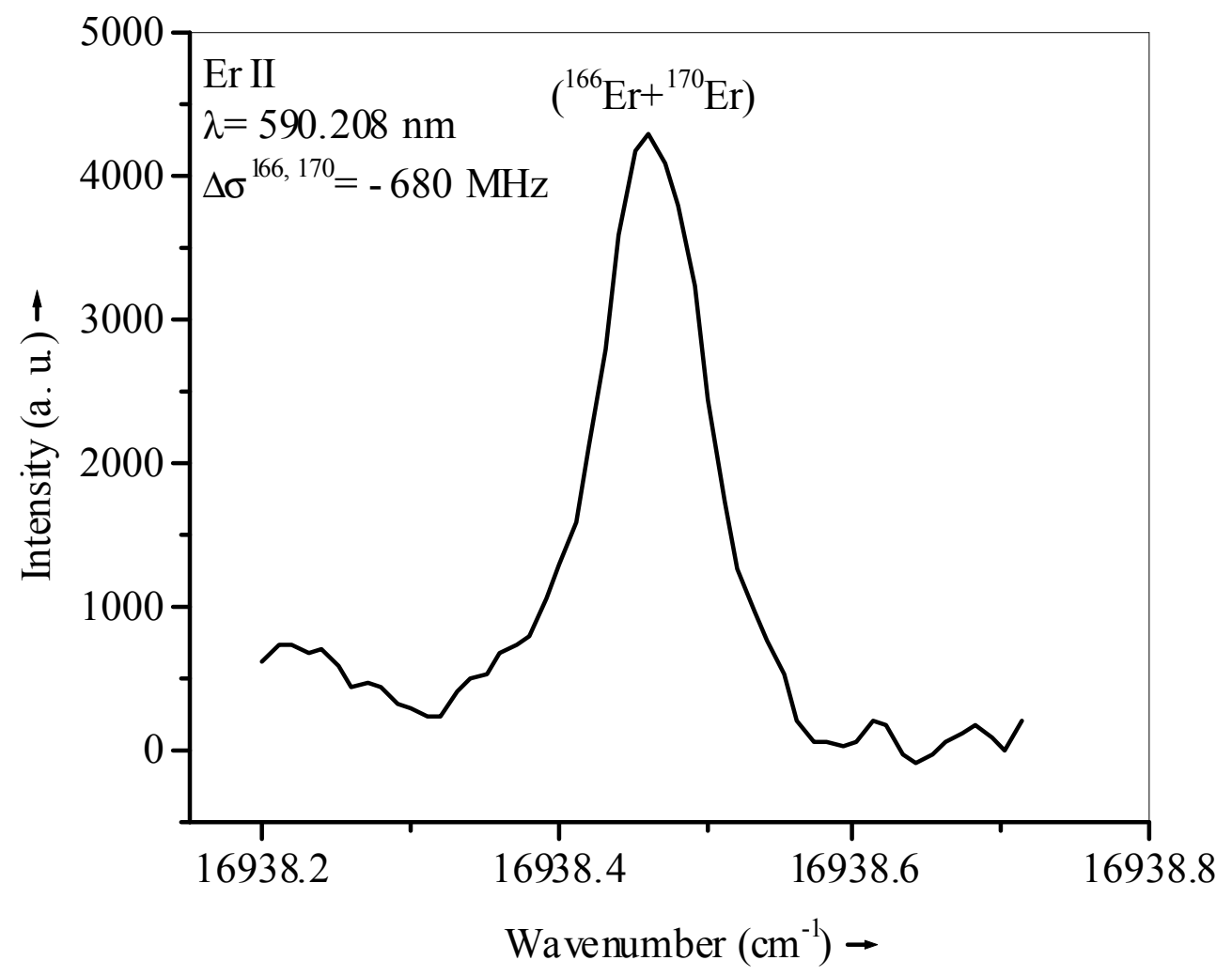

Figure 7. Er II FTS Spectrum, Wavelength, $\lambda=590.208 \mathrm{~nm}$ [Wavenumber, $\sigma=16938.483 \mathrm{~cm}^{-1}$, energy level classification $17378.917 \mathrm{~cm}^{-1}(\mathrm{~J}=13 / 2) 4 f^{11} 5 \mathrm{~d} 6 \mathrm{~s}$ $\left.\Delta T^{166,170}(2311 \mathrm{MHz})-440.434 \mathrm{~cm}^{-1}(J=11 / 2) 4 f^{12} 6 s \Delta T^{166,170}(2990 \mathrm{MHz})\right]$. The extracted $\Delta \sigma^{166,170}=-680 \mathrm{MHz}$. Light Source: Liquid nitrogen cooled HCL, Detector: $P M T$.

Table 2. List of IS, $\Delta \sigma^{166,170}(\mathrm{MHz})$ data in the spectral lines of the Er II in the wavelength region of 350-590 $\mathrm{nm}$. a. u.: Arbitrary units. The wavelengths and the energy level classifications are referred from Meggers et al. [9]. A: Wyart et al. [6] have rejected the energy level classification provided (in the parenthesis) by Meggers et al. [9]. B: Energy level classification of this line has been taken from Wyart et al. [6] since this line was unclassified in [9].

\begin{tabular}{|c|c|c|c|c|c|c|}
\hline$\lambda(\mathrm{nm})$ & Intensity (a. u.) & Odd $\left(\mathrm{cm}^{-1}\right)$ & $\mathrm{LIS}, \Delta \mathrm{T}^{166,170} \mathrm{MHz}$ & Even $\left(\mathrm{cm}^{-1}\right)$ & LIS, $\Delta T^{166,170}(\mathrm{MHz})$ & IS, $\Delta \sigma^{166,170}(\mathrm{MHz})$ \\
\hline 349.910 & 6700 & 29011 & 1071 & 440 & 2990 & -1920 \\
\hline 352.491 & 610 & 28361 & 2132 & 0 & 3000 & -870 \\
\hline 355.990 & 1000 & 28082 & 2051 & 0 & 3000 & -950 \\
\hline $357.075^{\mathrm{A}}$ & 920 & (33129) & 83 & (5132) & 2991 & -2910 \\
\hline 358.052 & 1000 & 28361 & 2132 & 440 & 2990 & -850 \\
\hline 359.983 & 1000 & 10667 & 2399 & 38438 & 2256 & -145 \\
\hline 361.656 & 3100 & 27642 & 2159 & 0 & 3000 & -840 \\
\hline 361.892 & 510 & 33028 & 1711 & 5403 & 2990 & -1280 \\
\hline 363.354 & 1000 & 27513 & 2798 & 0 & 3000 & -200 \\
\hline 363.716 & 270 & 32619 & 2268 & 5132 & 2991 & -725 \\
\hline 364.594 & 900 & 13027 & 2400 & 40447 & 2251 & 0 \\
\hline 365.287 & 500 & 34563 & 904 & 7195 & 2990 & -2090 \\
\hline 368.270 & 500 & 34341 & 1990 & 7195 & 2990 & -1000 \\
\hline 368.428 & 380 & 32267 & 1902 & 5132 & 2991 & -1090 \\
\hline 369.265 & 7900 & 27513 & 2798 & 440 & 2990 & -190 \\
\hline 369.625 & 450 & 34196 & 2382 & 7149 & 2991 & -610 \\
\hline 369.692 & 160 & 16935 & 2229 & 43977 & 2251 & 0 \\
\hline 371.239 & 520 & 6824 & 6430 & 33753 & 2671 & -3760 \\
\hline 372.364 & 65 & 39447 & 1775 & 12600 & 2991 & -1215 \\
\hline 372.952 & 1300 & 26805 & 1595 & 0 & 3000 & -1405 \\
\hline 373.126 & 450 & 33988 & 1854 & 7195 & 2990 & -1135 \\
\hline 373.458 & 270 & 26769 & 2332 & 0 & 3000 & -670 \\
\hline 374.110 & 340 & 6824 & 6430 & 33547 & 2682 & -3750 \\
\hline 374.264 & 900 & 31844 & 1641 & 5132 & 2991 & -1350 \\
\hline 374.571 & 55 & 39277 & 2048 & 12587 & 2991 & -950 \\
\hline 375.054 & 190 & 13338 & 6374 & 39994 & 2569 & -3805 \\
\hline 377.566 & 230 & 16935 & 2229 & 43413 & 2256 & 0 \\
\hline 378.447 & 310 & 33565 & 2093 & 7149 & 2991 & -900 \\
\hline 378.684 & 1800 & 26399 & 2338 & 0 & 3000 & -660 \\
\hline 379.706 & 560 & 26769 & 2332 & 440 & 2990 & -660 \\
\hline
\end{tabular}




\begin{tabular}{|c|c|c|c|c|c|c|}
\hline$\lambda(\mathrm{nm})$ & Intensity (a. u.) & $\operatorname{Odd}\left(\mathrm{cm}^{-1}\right)$ & LIS, $\Delta \mathrm{T}^{166,170} \mathrm{MHz}$ & Even $\left(\mathrm{cm}^{-1}\right)$ & LIS, $\Delta T^{166,170}(\mathrm{MHz})$ & IS, $\Delta \sigma^{166,170}(\mathrm{MHz})$ \\
\hline 383.048 & 3600 & 26098 & 1595 & 0 & 3000 & -1410 \\
\hline 383.926 & 950 & 16948 & 5876 & 42987 & 2255 & -3620 \\
\hline 384.831 & 80 & 31381 & 3020 & 5403 & 2990 & 0 \\
\hline 388.061 & 1500 & 30894 & 1781 & 5132 & 2991 & -1210 \\
\hline 388.289 & 1200 & 32896 & 1639 & 7149 & 2991 & -1350 \\
\hline 389.061 & 400 & 36738 & 1208 & 11042 & 2991 & -1785 \\
\hline 389.623 & 5200 & 26098 & 1595 & 440 & 2990 & -1400 \\
\hline 390.276 & 810 & 32811 & 1493 & 7195 & 2990 & -1500 \\
\hline 390.384 & 50 & 17378 & 2311 & 42987 & 2255 & 0 \\
\hline 390.631 & 11000 & 25592 & 2798 & 0 & 3000 & -200 \\
\hline 391.242 & 140 & 11309 & 2399 & 36861 & 2680 & +280 \\
\hline 392.188 & 280 & 30894 & 1781 & 5403 & 2990 & -1210 \\
\hline 393.225 & 810 & 32619 & 2268 & 7195 & 2990 & -725 \\
\hline 393.863 & 2100 & 25382 & 2141 & 0 & 3000 & -860 \\
\hline 393.892 & 85 & 17842 & 2188 & 43223 & 2289 & -100 \\
\hline 397.472 & 1400 & 25592 & 2798 & 440 & 2990 & -190 \\
\hline 400.916 & 280 & 24935 & 2184 & 0 & 3000 & -825 \\
\hline 401.557 & 350 & 30028 & 2060 & 5132 & 2991 & -930 \\
\hline 404.624 & 270 & 31902 & 2083 & 7195 & 2990 & -910 \\
\hline 404.949 & 200 & 24687 & 2378 & 0 & 3000 & -625 \\
\hline 405.547 & 940 & 29783 & 1793 & 5132 & 2991 & -1200 \\
\hline 405.978 & 690 & 30028 & 2060 & 5403 & 2990 & -930 \\
\hline 408.124 & 550 & 24935 & 2184 & 440 & 2990 & -825 \\
\hline 409.464 & 140 & 24415 & 2345 & 0 & 3000 & -655 \\
\hline 410.398 & 60 & 29492 & 2089 & 5132 & 2991 & -900 \\
\hline 414.291 & 550 & 29263 & 1446 & 5132 & 2991 & -1551 \\
\hline 427.648 & 140 & 12815 & 2395 & 36192 & 2678 & +285 \\
\hline 430.160 & 320 & 23241 & 2233 & 0 & 3000 & -770 \\
\hline 430.381 & 60 & 28361 & 2132 & 5132 & 2991 & -860 \\
\hline 433.900 & 50 & 14280 & 2400 & 37321 & 2677 & +275 \\
\hline 438.470 & 300 & 23241 & 2233 & 440 & 2990 & -760 \\
\hline 441.961 & 570 & 13572 & 2400 & 36192 & 2678 & +280 \\
\hline 445.924 & 100 & 22859 & 2375 & 440 & 2990 & -625 \\
\hline 450.075 & 200 & 14649 & 2400 & 36861 & 2680 & +280 \\
\hline 467.562 & 570 & 10667 & 2399 & 32048 & 2688 & +290 \\
\hline 467.906 & 150 & 12388 & 2400 & 33753 & 2671 & +165 \\
\hline 473.159 & 85 & 15732 & 2400 & 36861 & 2680 & +280 \\
\hline 475.965 & 170 & 21004 & 2261 & 0 & 3000 & -740 \\
\hline 476.264 & 60 & 16643 & 2375 & 37634 & 2682 & +310 \\
\hline 482.035 & 190 & 11309 & 2399 & 32048 & 2688 & +290 \\
\hline 483.115 & 85 & 13060 & 2408 & 33753 & 2671 & +265 \\
\hline 485.164 & 30 & 17063 & 2798 & 37669 & 2626 & -175 \\
\hline 487.209 & 150 & 13027 & 2400 & 33547 & 2682 & +280 \\
\hline 487.248 & 30 & 20517 & 2362 & 0 & 3000 & -640 \\
\hline 490.008 & 210 & 12815 & 2395 & 33217 & 2609 & +215 \\
\hline 493.411 & 210 & 23973 & 926 & 44235 & 2058 & +1135 \\
\hline $495.360^{\mathrm{B}}$ & 45 & 24053 & 880 & 44235 & 2058 & +1180 \\
\hline 500.038 & 90 & 19992 & 2175 & 0 & 3000 & -825 \\
\hline $502.428^{\mathrm{B}}$ & 45 & 20319 & 2368 & 40217 & 2677 & +310 \\
\hline 502.891 & 120 & 20319 & 2368 & 440 & 2990 & -625 \\
\hline 504.205 & 210 & 13719 & 2392 & 33547 & 2682 & +290 \\
\hline 518.890 & 160 & 14280 & 2400 & 33547 & 2682 & +280 \\
\hline $521.826^{\mathrm{B}}$ & 30 & 28016 & 852 & 47174 & 2253 & +1400 \\
\hline 525.593 & 140 & 13027 & 2400 & 32048 & 2688 & +290 \\
\hline 590.208 & 27 & 17378 & 2311 & 440 & 2990 & -680 \\
\hline
\end{tabular}

\subsection{Electron Configurations and Their Screening Ratios}

Transition IS defined as the difference between the energies of upper and lower energy levels (LIS) of two different isotopes. IS in a line consists mainly of mass shifts (MS) and field isotope shifts (FIS) or field shift (FS). MS further divided into the normal mass shift (NMS) and specific mass shifts (SMS). MS dominates in lighter elements whereas FS dominates in the high $\mathrm{Z}$ elements with mass number, $\mathrm{A} \geq 100$. FS is observed due to the change in $n s$ and in small extent in $n p$ electron densities at the nucleus or simply due to change in size and shape of the nuclei [15]. FS varies according to number of $n s$ electrons present in the configuration and hence helps in identifying the definite configuration if LIS data is available for that energy level. However $n p$ and $n d$ electrons screen the $n s$ - electron in the given configuration thus amount of screening is different for different configurations. It has been observed that the 
screening ratios of $n s$ - electron densities for different configurations are proportional to the ratios of respective LIS of the pure configurations [16]. The task of identifying the configuration for the particular high lying level becomes theoretically difficult because of the favorable chances of configuration mixing. The configuration mixing takes place between two or more configurations of the close lying energy levels provided these energy levels have same parity and the same $J$. The LIS, $\Delta \mathrm{T}^{166,170}(\mathrm{MHz})$ were estimated using the well-known "Sharing Rule" (see eq. 1) according to which a state whose wave function ( $\Psi$ ) results from mixing of ' $n$ ' number of configurations, the LIS, $\Delta \mathrm{T}$ equals the sum of LIS, $\Delta \mathrm{T}_{i}$ of individual configurations, multiplied by square of weight $\mathrm{C}_{i}$ of the configurations in $\Psi$,

$$
\Delta T=\sum_{i=1}^{n} C_{i}^{2} \Delta T \text { with } \quad \sum C_{i}^{2}=1
$$

We evaluated the hypothetical $\Delta \mathrm{T}$ values for the even and odd energy levels with the aid of various percentage compositions of different configurations. The even levels have configuration mixing of the type $\left(4 f^{12} 6 s+4 f^{12} 5 d+4 f^{11} 6 s 6 p+4 f^{11} 5 d 6 p\right)$ whereas the odd levels have of the type $\left(4 \mathrm{f}^{11} 6 \mathrm{~s}^{2}+4 \mathrm{f}^{11} 5 \mathrm{~d} 6 \mathrm{~s}+4 \mathrm{f}^{12} 6 \mathrm{p}+4 \mathrm{f}^{11} 5 \mathrm{~d}^{2}\right)$ as has been provided in Wyart et al. [6].

The LIS of different even and odd levels of Er II were derived using the transition arrays, the different screening ratios published in reference [16] and the LIS, $\Delta \mathrm{T}^{166,170} 4800 \mathrm{MHz}$ $\left(0.160 \mathrm{~cm}^{-1}\right)$ of the ground state level of $4 \mathrm{f}^{12} 6 \mathrm{~s}^{2}$ configuration of Er I [14]. LIS $\Delta \mathrm{T}^{166,170} 3000 \mathrm{MHz}\left(0.100 \mathrm{~cm}^{-1}\right)$ in the ground state level of $4 \mathrm{f}^{12} 6 \mathrm{~s}$ configuration was calculated using the empirical screening ratio provided in [16] $\Delta \mathrm{T}\left(4 f^{2} 6 s^{2}\right) / \Delta \mathrm{T}$ $\left(4 f^{2} 6 s\right)=1.6$. Some of the screening ratios derived presently for the even and odd configurations of Er II are summarized here;

$$
\begin{gathered}
\Delta \mathrm{T}\left(4 f^{2} 6 s^{2}\right) / \Delta \mathrm{T}\left(4 f^{2} 6 s\right)=1.6, \Delta \mathrm{T}\left(4 f^{11} 6 s 6 p\right) / \Delta \mathrm{T}\left(4 f^{22} 6 s\right)= \\
0.9, \Delta \mathrm{T}\left(4 f^{11} 6 s 5 d\right] / \Delta \mathrm{T}\left(4 f^{2} 6 s\right)=0.8, \Delta \mathrm{T}\left(4 f^{2} 6 s\right) / \Delta \mathrm{T}\left(4 f^{12} 6 p\right) \\
=5.0, \text { and } \Delta \mathrm{T}\left(4 f^{11} 6 s^{2}\right) / \Delta \mathrm{T}\left(4 f^{12} 6 s\right)=2.2
\end{gathered}
$$

Table 3. Pure Even and odd configurations with their expected LIS, $\Delta T^{166,170}$ (MHz) of Er II.

\begin{tabular}{llll}
\hline $\begin{array}{l}\text { Even } \\
\text { Configuration }\end{array}$ & $\begin{array}{l}\Delta \mathbf{T}^{166,170} \\
(\mathbf{M H z})\end{array}$ & $\begin{array}{l}\text { Odd } \\
\text { Configuration }\end{array}$ & $\begin{array}{l}\Delta \mathbf{T}^{\mathbf{1 6 6}, \mathbf{1 7 0}} \\
(\mathbf{M H z})\end{array}$ \\
\hline $4 \mathrm{f}^{12} 6 \mathrm{~s}^{2}$ & 4800 & $4 \mathrm{f}^{11} 6 \mathrm{~s}^{2}$ & 6600 \\
$4 \mathrm{f}^{12} 6 \mathrm{~s}$ & 3000 & $4 \mathrm{f}^{11} 6 \mathrm{~s} 5 \mathrm{~d}$ & 2400 \\
$4 \mathrm{f}^{12} 5 \mathrm{~d}$ & 0 & $4 \mathrm{f}^{11} 5 \mathrm{~d}^{2}$ & 850 \\
$4 \mathrm{f}^{11} 6 \mathrm{~s} 6 \mathrm{p}$ & 2700 & $4 \mathrm{f}^{12} 6 \mathrm{p}$ & 600 \\
$4 \mathrm{f}^{11} 5 \mathrm{~d} 6 \mathrm{p}$ & 2250 & & \\
\hline
\end{tabular}

LIS of pure configurations of Er II derived using the above mentioned screening ratios and these were listed in the Table 3. Fig. 4 depicts the partial energy level diagram for the Er II spectrum encompassing the different types of transitions, IS $\Delta \sigma^{166,170}$ (MHz) data, different configurations, and their LIS, $\Delta \mathrm{T}^{166,170}(\mathrm{MHz})$. LIS data was derived with the accuracy of \pm $0.003 \mathrm{~cm}^{-1}( \pm 90 \mathrm{MHz})$ accordingly for 29 even and 63 odd levels and presented in Table 4 and 5.

\subsubsection{Even Parity Energy Levels and Their Configuration Mixing}

Column 1 and 2 in the Table 4 exhibit the previous status of configuration assignment whereas column 3 shows the present experimental LIS, $\Delta \mathrm{T}^{166,}{ }^{170}$ data and the configuration mixing suggested by us. We have derived the hypothetical LIS $\Delta \mathrm{T}$ values for the energy levels encountered in the present studies using the different possible configuration mixings and listed those along with the experimentally derived LIS $\Delta$ Ts. All the 29 even parity energy levels exhibit configuration mixings of the type $\left(4 f^{12} 6 s+4 f^{12} 5 d+4 f^{11} 6 s 6 p+4 f^{11} 5 d 6 p\right)$ of the different configurations. As seen in the Table, the experimental LIS values and LIS values derived using 'Sharing rule' do not wonder much from each other. Thus the theoretically predicted configuration mixings for all even levels as reported in [6] were confirmed experimentally.

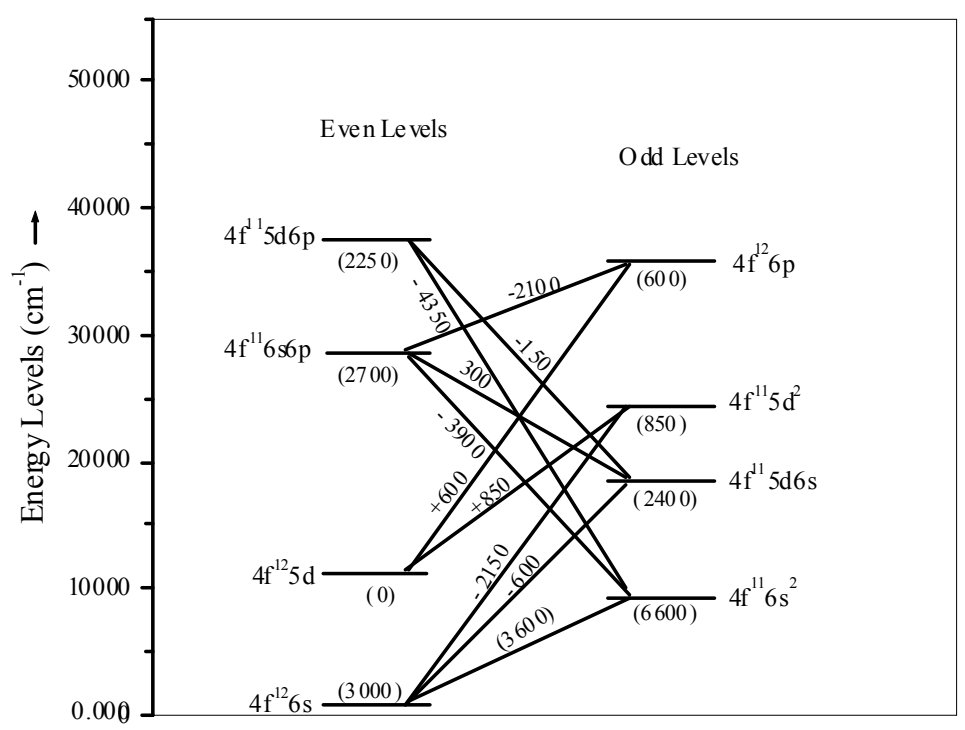

Figure 8. Partial energy level scheme, Horizontal lines represent energy levels, vertical lines represent the transitions, values across the transitions represent $I S, \Delta \sigma^{166,170}(\mathrm{MHz})$, values in the parenthesis represent LIS, $\Delta T^{166,170}(\mathrm{MHz})$ of the pure configuration. 
Table 4. The LIS, $\Delta T^{166,170}(\mathrm{MHz})$ derived in the even- parity levels of Er II. a: The new level referred from [6].

\begin{tabular}{|c|c|c|c|c|c|c|c|c|c|c|c|c|}
\hline \multicolumn{3}{|l|}{ [1] } & \multicolumn{4}{|c|}{ Configuration Mixing (\%) [6] } & \multicolumn{3}{|c|}{ Present work $\leftarrow(\mathrm{MHz})$} & \multicolumn{3}{|c|}{$\rightarrow \leftarrow$ Configuration mixing $(\%) \rightarrow$} \\
\hline Level $\left(\mathrm{cm}^{-1}\right)$ & configuration & $\mathbf{J}$ & $4 f^{12} 6 s$ & $4 f^{12} 5 d$ & $4 f^{11} 6 s 6 p$ & $4 f^{11} 5 d 6 p$ & $\Delta \mathrm{T}_{\mathrm{FTS}}$ & $\Delta T_{\text {Sharing rule }}$ & $4 f^{12} 6 s$ & $4 f^{12} 5 d$ & $4 f^{11} 6 s 6 p$ & $4 f^{11} 5 d 6 p$ \\
\hline 0.000 & $4 \mathrm{f}^{12} 6 \mathrm{~s}$ & $13 / 2$ & 98.85 & 0.01 & 0.01 & 1.13 & 3000 & 2991.195 & 98.85 & 0.01 & 0.01 & 1.13 \\
\hline 440.434 & $4 f^{12} 6 s$ & $11 / 2$ & 98.81 & 0.02 & 0.01 & 1.15 & 2990 & 2990.445 & 98.81 & 0.02 & 0.01 & 1.15 \\
\hline 5132.608 & $4 f^{12} 6 s$ & $9 / 2$ & 98.82 & 0.01 & 0.02 & 1.15 & 2991 & 2991.015 & 98.82 & 0.01 & 0.02 & 1.15 \\
\hline 5403.688 & $4 f^{12} 6 s$ & $7 / 2$ & 98.80 & 0.03 & 0.02 & 1.15 & 2990 & 2990.415 & 98.80 & 0.03 & 0.02 & 1.15 \\
\hline 7149.630 & $4 f^{12} 6 s$ & $11 / 2$ & 98.83 & 0.02 & 0.01 & 1.14 & 2991 & 2990.82 & 98.83 & 0.02 & 0.01 & 1.14 \\
\hline 7195.355 & $4 f^{12} 6 s$ & $9 / 2$ & 98.82 & 0.02 & 0.01 & 1.15 & 2990 & 2990.745 & 98.82 & 0.02 & 0.01 & 1.15 \\
\hline 10893.936 & $4 f^{12} 6 s$ & $7 / 2$ & 98.81 & 0.02 & 0.02 & 1.15 & 2991 & 2990.715 & 98.81 & 0.02 & 0.02 & 1.15 \\
\hline 11042.640 & $4 f^{12} 6 s$ & $9 / 2$ & 98.81 & 0.03 & 0.02 & 1.15 & 2991 & 2990.715 & 98.81 & 0.03 & 0.02 & 1.15 \\
\hline 12587.998 & $4 f^{12} 6 s$ & $7 / 2$ & 98.78 & 0.03 & 0.03 & 1.17 & 2991 & 2990.535 & 98.78 & 0.03 & 0.03 & 1.17 \\
\hline 12600.093 & $4 f^{12} 6 s$ & $5 / 2$ & 98.79 & 0.02 & 0.03 & 1.16 & 2991 & 2990.61 & 98.79 & 0.02 & 0.03 & 1.16 \\
\hline 32048.749 & $4 f^{11} 6 s 6 p$ & $15 / 2$ & 0.00 & 0.00 & 97.49 & 2.51 & 2688 & 2688.705 & 0.00 & 0.00 & 97.49 & 2.51 \\
\hline 33217.200 & $4 f^{11} 6 s 6 p$ & $17 / 2$ & 0.06 & 0.00 & 95.61 & 4.39 & 2682 & 2682.045 & 0.06 & 0.00 & 95.61 & 4.39 \\
\hline 33547.268 & $4 f^{11} 6 s 6 p$ & $15 / 2$ & 0.00 & 0.00 & 95.97 & 4.03 & 2682 & 2681.865 & 0.00 & 0.00 & 95.97 & 4.03 \\
\hline 33753.920 & $4 f^{11} 6 s 6 p$ & $13 / 2$ & 0.01 & 0.08 & 93.96 & 5.96 & 2671 & 2671.32 & 0.01 & 0.08 & 93.96 & 5.96 \\
\hline 36192.206 & $4 f^{11} 6 s 6 p$ & $19 / 2$ & 0.00 & 0.00 & 95.33 & 4.67 & 2678 & 2678.985 & 0.00 & 0.00 & 95.33 & 4.67 \\
\hline 36861.561 & $4 f^{11} 6 s 6 p$ & $17 / 2$ & 0.00 & 0.00 & 95.63 & 4.37 & 2680 & 2680.335 & 0.00 & 0.00 & 95.63 & 4.37 \\
\hline 37321.029 & $4 f^{11} 6 s 6 p$ & $15 / 2$ & 0.00 & 0.01 & 94.95 & 5.04 & 2677 & 2677.05 & 0.00 & 0.01 & 94.95 & 5.04 \\
\hline 37634.115 & $4 f^{11} 6 s 6 p$ & $13 / 2$ & 0.00 & 0.05 & 96.21 & 3.73 & 2682 & 2681.595 & 0.00 & 0.05 & 96.21 & 3.73 \\
\hline 37669.535 & $4 f^{11} 6 s 6 p$ & $11 / 2$ & 0.01 & 1.94 & 93.31 & 4.74 & 2626 & 2626.02 & 0.01 & 1.94 & 93.31 & 4.74 \\
\hline 38438.391 & $4 \mathrm{f}^{11} 5 \mathrm{~d} 6 \mathrm{p} ?$ & $11 / 2$ & 0.00 & 0.00 & 1.37 & 98.63 & 2256 & 2256.165 & 0.00 & 0.00 & 1.37 & 98.63 \\
\hline 39994.031 & $4 f^{11} 6 s 6 p ?$ & $15 / 2$ & 0.00 & 0.00 & 70.99 & 29.01 & 2569 & 2569.455 & 0.00 & 0.00 & 70.99 & 29.01 \\
\hline $40217.711^{\mathrm{a}}$ & & $11 / 2$ & 0.00 & 0.05 & 95.13 & 4.82 & 2677 & 2676.96 & 0.00 & 0.05 & 95.13 & 4.82 \\
\hline 40447.910 & $4 \mathrm{f}^{11} 5 \mathrm{~d} 6 \mathrm{p} ?$ & $19 / 2$ & 0.00 & 0.00 & 0.26 & 99.74 & 2251 & 2251.17 & 0.00 & 0.00 & 0.26 & 99.74 \\
\hline 42987.453 & $4 \mathrm{f}^{11} 5 \mathrm{~d} 6 \mathrm{p} ?$ & $11 / 2$ & 0.00 & 0.01 & 1.29 & 98.68 & 2255 & 2255.13 & 0.00 & 0.01 & 1.29 & 98.68 \\
\hline 43223.145 & $4 \mathrm{f}^{11} 5 \mathrm{~d} 6 \mathrm{p} ?$ & $15 / 2$ & 0.00 & 0.01 & 4.31 & 96.58 & 2289 & 2289.42 & 0.00 & 0.01 & 4.31 & 96.58 \\
\hline 43413.717 & $4 \mathrm{f}^{11} 5 \mathrm{~d} 6 \mathrm{p} ?$ & $19 / 2$ & 0.00 & 0.00 & 1.32 & 98.68 & 2256 & 2255.94 & 0.00 & 0.00 & 1.32 & 98.68 \\
\hline 43977.651 & & $19 / 2$ & 0.00 & 0.00 & 0.18 & 99.82 & 2251 & 2251.17 & 0.00 & 0.00 & 0.18 & 99.82 \\
\hline 44235.276 & & $17 / 2$ & 0.00 & 0.00 & 8.54 & 91.45 & 2058 & 2058.71 & 0.00 & 0.00 & 8.54 & 91.45 \\
\hline 47174.273 & & $17 / 2$ & 0.00 & 0.01 & 0.67 & 99.20 & 2253 & 2253.42 & 0.00 & 0.01 & 0.67 & 99.20 \\
\hline
\end{tabular}

Table 5. The list of the odd parity energy levels of Er II and their LIS, $\Delta T^{166,170}$ values in MHz. A: This is newly calculated level taken from [6]. B: The unassigned level at $32811.006 \mathrm{~cm}^{-1}$ tabulated in [1] was revised to $32810.980 \mathrm{~cm}^{-1}$ in reference [6].

\begin{tabular}{|c|c|c|c|c|c|c|c|c|c|c|c|c|}
\hline \multicolumn{3}{|l|}{ [1] } & \multicolumn{4}{|c|}{ Configuration mixing (\%) [6] } & \multicolumn{6}{|c|}{ Present work $\leftarrow(\mathrm{MHz}) \rightarrow \leftarrow$ Configuration mixing $(\%) \rightarrow$} \\
\hline Level $\left(\mathrm{cm}^{-1}\right)$ & Configuration & $\mathbf{J}$ & $4 f^{11} 6 s^{2}$ & $4 f^{11} 5 d 6 s$ & $4 f^{12} 6 p$ & $4 f^{11} 5 d^{2}$ & $\Delta \mathrm{T}_{\mathrm{FTS}}$ & $\Delta \mathrm{T}_{\text {Sharing rule }}$ & $4 f^{11} 6 s^{2}$ & $4 f^{11} 5 \mathrm{~d} 6 \mathrm{~s}$ & $4 f^{12} 6 p$ & $4 f^{11} 5 d^{2}$ \\
\hline 6824.774 & $4 \mathrm{f}^{11} 6 \mathrm{~s}^{2}$ & $15 / 2$ & 97.04 & 0.04 & 0.00 & 2.91 & 6430 & 6430.335 & 97.04 & 0.04 & 0.00 & 2.91 \\
\hline 10667.165 & $4 \mathrm{f}^{11} 5 \mathrm{~d} 6 \mathrm{~s}$ & $13 / 2$ & 0.00 & 99.97 & 0.00 & 0.02 & 2399 & 2399.45 & 0.00 & 99.97 & 0.00 & 0.02 \\
\hline 11309.180 & $4 \mathrm{f}^{11} 5 \mathrm{~d} 6 \mathrm{~s}$ & $15 / 2$ & 0.01 & 99.91 & 0.00 & 0.08 & 2399 & 2400.62 & 0.01 & 99.91 & 0.00 & 0.08 \\
\hline 12388.090 & $4 f^{11} 5 \mathrm{~d} 6 \mathrm{~s}$ & $11 / 2$ & 0.01 & 99.78 & 0.03 & 1.18 & 2400 & 2405.59 & 0.01 & 99.78 & 0.03 & 1.18 \\
\hline 12815.043 & $4 f^{11} 5 d 6 s$ & $19 / 2$ & 0.00 & 99.61 & 0.00 & 0.39 & 2395 & 2393.955 & 0.00 & 99.61 & 0.00 & 0.39 \\
\hline 13027.927 & $4 \mathrm{f}^{11} 5 \mathrm{~d} 6 \mathrm{~s}$ & $17 / 2$ & 0.00 & 99.99 & 0.00 & 0.01 & 2400 & 2399.845 & 0.00 & 99.99 & 0.00 & 0.01 \\
\hline 13060.693 & $4 f^{11} 5 d 6 s$ & $13 / 2$ & 0.79 & 97.58 & 0.04 & 1.60 & 2408 & 2407.90 & 0.79 & 97.58 & 0.04 & 1.60 \\
\hline 13338.777 & $4 f^{11} 6 s^{2}$ & $13 / 2$ & 96.26 & 0.84 & 0.00 & 2.90 & 6376 & 6397.97 & 96.26 & 0.84 & 0.00 & 2.90 \\
\hline 13572.118 & $4 f^{11} 5 d 6 s$ & $21 / 2$ & 0.00 & 100.00 & 0.00 & 0.00 & 2400 & 2400.00 & 0.00 & 100.00 & 0.00 & 0.00 \\
\hline 13719.562 & $4 f^{11} 5 d 6 s$ & $17 / 2$ & 0.00 & 99.46 & 0.00 & 0.54 & 2392 & 2391.63 & 0.00 & 99.46 & 0.00 & 0.54 \\
\hline 14280.723 & $4 f^{11} 5 d 6 s$ & $15 / 2$ & 0.00 & 99.44 & 0.03 & 0.53 & 2400 & 2391.245 & 0.00 & 99.44 & 0.03 & 0.53 \\
\hline 14649.277 & $4 \mathrm{f}^{11} 5 \mathrm{~d} 6 \mathrm{~s}$ & $19 / 2$ & 0.00 & 99.98 & 0.00 & 0.02 & 2400 & 2399.69 & 0.00 & 99.98 & 0.00 & 0.02 \\
\hline 15732.917 & $4 \mathrm{f}^{11} 5 \mathrm{~d} 6 \mathrm{~s}$ & $17 / 2$ & 0.00 & 99.90 & 0.00 & 0.10 & 2400 & 2398.45 & 0.00 & 99.90 & 0.00 & 0.10 \\
\hline 16643.237 & $4 \mathrm{f}^{11} 5 \mathrm{~d} 6 \mathrm{~s}$ & $13 / 2$ & 0.00 & 97.89 & 0.98 & 1.13 & 2375 & 2364.845 & 0.00 & 97.89 & 0.98 & 1.13 \\
\hline 16935.811 & $4 f^{11} 5 d 6 s$ & $19 / 2$ & 0.00 & 88.99 & 0.00 & 11.01 & 2229 & 2229.345 & 0.00 & 88.99 & 0.00 & 11.01 \\
\hline 16948.197 & $4 f^{11} 6 s^{2}$ & $11 / 2$ & 84.30 & 12.86 & 0.08 & 2.75 & 5876 & 5896.295 & 84.30 & 12.86 & 0.08 & 2.75 \\
\hline 17063.709 & $4 \mathrm{f}^{11} 5 \mathrm{~d} 6 \mathrm{~s}$ & $11 / 2$ & 10.74 & 86.03 & 0.35 & 2.88 & 2798 & 2800.14 & 10.74 & 86.03 & 0.35 & 2.88 \\
\hline 17378.917 & $4 f^{11} 5 d 6 s$ & $13 / 2$ & 0.02 & 94.26 & 0.51 & 5.21 & 2311 & 2310.905 & 0.02 & 94.26 & 0.51 & 5.21 \\
\hline 17842.664 & $4 f^{11} 5 d 6 s$ & $17 / 2$ & 0.00 & 86.34 & 0.00 & 13.66 & 2188 & 2188.27 & 0.00 & 86.34 & 0.00 & 13.66 \\
\hline 19992.895 & $4 f^{11} 5 d 6 s$ & $11 / 2$ & 0.20 & 89.45 & 1.60 & 8.74 & 2175 & 2243.89 & 0.20 & 89.45 & 1.60 & 8.74 \\
\hline 20319.934 & $4 \mathrm{f}^{11} 5 \mathrm{~d} 6 \mathrm{~s}$ & $13 / 2$ & 0.00 & 98.11 & 1.04 & 0.85 & 2368 & 2368.105 & 0.00 & 98.11 & 1.04 & 0.85 \\
\hline 20517.717 & - & $15 / 2$ & 0.01 & 97.68 & 0.88 & 1.43 & 2362 & 2362.415 & 0.01 & 97.68 & 0.88 & 1.43 \\
\hline 21004.060 & $4 f^{115 d 6 s}$ & $13 / 2$ & 0.00 & 91.70 & 4.00 & 4.30 & 2261 & 2261.35 & 0.00 & 91.70 & 4.00 & 4.30 \\
\hline 22859.510 & $4 \mathrm{f}^{11} 5 \mathrm{~d} 6 \mathrm{~s} ?$ & $13 / 2$ & 0.00 & 98.49 & 0.42 & 1.09 & 2375 & 2375.545 & 0.00 & 98.49 & 0.42 & 1.09 \\
\hline 23240.649 & - & $11 / 2$ & 0.06 & 89.74 & 4.55 & 5.65 & 2233 & 2233.045 & 0.06 & 89.74 & 4.55 & 5.65 \\
\hline
\end{tabular}




\begin{tabular}{|c|c|c|c|c|c|c|c|c|c|c|c|c|}
\hline \multicolumn{3}{|l|}{ [1] } & \multicolumn{4}{|c|}{ Configuration mixing (\%) [6] } & \multicolumn{6}{|c|}{ Present work $\leftarrow(\mathrm{MHz}) \rightarrow \leftarrow$ Configuration mixing $(\%) \rightarrow$} \\
\hline Level $\left(\mathrm{cm}^{-1}\right)$ & Configuration & $\mathbf{J}$ & $4 f^{11} 6 s^{2}$ & $4 f^{11} 5 \mathrm{~d} 6 \mathrm{~s}$ & $4 f^{12} 6 p$ & $4 f^{11} 5 d^{2}$ & $\Delta \mathrm{T}_{\mathrm{FTS}}$ & $\Delta \mathrm{T}_{\text {Sharing rule }}$ & $4 f^{11} 6 s^{2}$ & $4 f^{115} 5 d 6 s$ & $4 f^{12} 6 p$ & $4 f^{11} 5 d^{2}$ \\
\hline 23973.877 & - & $15 / 2$ & 0.00 & 4.93 & 0.05 & 95.01 & 926 & 926.205 & 0.00 & 4.93 & 0.05 & 95.01 \\
\hline 24053.520 & - & $17 / 2$ & 0.00 & 1.92 & 0.00 & 98.08 & 880 & 879.76 & 0.00 & 1.92 & 0.00 & 98.08 \\
\hline 24415.265 & - & $11 / 2$ & 0.01 & 95.97 & 0.75 & 3.27 & 2345 & 2336.235 & 0.01 & 95.97 & 0.75 & 3.27 \\
\hline 24687.523 & - & $11 / 2$ & 0.02 & 98.67 & 1.13 & 0.18 & 2378 & 2377.71 & 0.02 & 98.67 & 1.13 & 0.18 \\
\hline 24935.855 & - & $13 / 2$ & 0.01 & 86.44 & 2.63 & 10.91 & 2184 & 2183.735 & 0.01 & 86.44 & 2.63 & 10.91 \\
\hline 25382.379 & - & $11 / 2$ & 0.37 & 84.37 & 12.55 & 2.71 & 2141 & 2147.635 & 0.37 & 84.37 & 12.55 & 2.71 \\
\hline 25592.343 & $4 \mathrm{f}^{12} 6 \mathrm{p} ?$ & $11 / 2$ & 0.92 & 40.35 & 46.15 & 12.58 & 2798 & 2800.14 & 0.92 & 40.35 & 46.15 & 12.58 \\
\hline 26098.957 & $4 f^{12} 6 p ?$ & $13 / 2$ & 0.01 & 54.98 & 43.06 & 1.95 & 1595 & 1595.115 & 0.01 & 54.98 & 43.06 & 1.95 \\
\hline 26399.775 & - & $11 / 2$ & 2.89 & 86.63 & 8.02 & 2.46 & 2338 & 2338.89 & 2.89 & 86.63 & 8.02 & 2.46 \\
\hline 26769.141 & - & $13 / 2$ & 0.00 & 95.96 & 2.29 & 1.75 & 2332 & 2331.655 & 0.00 & 95.96 & 2.29 & 1.75 \\
\hline 26805.448 & - & $11 / 2$ & 0.16 & 6.38 & 9.23 & 84.23 & 1595 & 1595.115 & 0.16 & 6.38 & 9.23 & 84.23 \\
\hline 27513.555 & - & $13 / 2$ & 0.00 & 54.95 & 40.56 & 4.48 & 2798 & 2800.14 & 10.74 & 86.03 & 0.35 & 2.88 \\
\hline 27642.658 & - & $11 / 2$ & 0.26 & 85.25 & 11.07 & 3.42 & 2159 & 2158.65 & 0.26 & 85.25 & 11.07 & 3.42 \\
\hline $28016.137^{\mathrm{A}}$ & - & $19 / 2$ & 0.00 & 0.12 & 0.00 & 99.88 & 852 & 851.86 & 0.00 & 0.12 & 0.00 & 99.88 \\
\hline 28082.701 & - & $13 / 2$ & 0.00 & 78.65 & 7.19 & 14.16 & 2051 & 2051.10 & 0.00 & 78.65 & 7.19 & 14.16 \\
\hline 28361.286 & - & $11 / 2$ & 0.31 & 83.08 & 9.27 & 7.35 & 2132 & 2132.475 & 0.31 & 83.08 & 9.27 & 7.35 \\
\hline 29011.015 & $4 f^{12} 6 p ?$ & $9 / 2$ & 0.01 & 24.21 & 61.99 & 13.80 & 1071 & 1070.94 & 0.01 & 24.21 & 61.99 & 13.80 \\
\hline 29263.402 & - & $7 / 2$ & 0.10 & 40.58 & 15.66 & 43.66 & 1446 & 1445.59 & 0.10 & 40.58 & 15.66 & 43.66 \\
\hline 29492.329 & $4 f^{12} 6 p ?$ & $11 / 2$ & 0.10 & 81.70 & 13.35 & 4.86 & 2089 & 2082.87 & 0.10 & 81.70 & 13.35 & 4.86 \\
\hline 29783.733 & - & $9 / 2$ & 0.26 & 62.86 & 18.47 & 18.41 & 1793 & 1793.105 & 0.26 & 62.86 & 18.47 & 18.41 \\
\hline 30028.618 & - & $9 / 2$ & 0.12 & 79.79 & 13.32 & 6.76 & 2060 & 2060.20 & 0.12 & 79.79 & 13.31 & 6.76 \\
\hline 30894.447 & $4 f^{12} 6 p ?$ & $7 / 2$ & 0.02 & 64.74 & 29.44 & 5.80 & 1781 & 1781.02 & 0.02 & 64.74 & 29.44 & 5.80 \\
\hline 31381.779 & - & $9 / 2$ & 19.85 & 67.39 & 5.25 & 7.51 & 3020 & 3022.795 & 19.85 & 67.39 & 5.25 & 7.51 \\
\hline 31844.124 & - & $9 / 2$ & 0.92 & 53.52 & 36.10 & 9.46 & 1641 & 1642.21 & 0.92 & 53.52 & 36.10 & 9.46 \\
\hline 31902.682 & - & $7 / 2$ & 0.01 & 81.26 & 10.74 & 7.99 & 2083 & 2083.255 & 0.01 & 81.26 & 10.74 & 7.99 \\
\hline 32267.246 & - & $9 / 2$ & 0.06 & 69.91 & 13.89 & 16.14 & 1902 & 1902.33 & 0.06 & 69.91 & 13.89 & 16.14 \\
\hline 32618.753 & - & $11 / 2$ & 3.15 & 81.47 & 9.87 & 5.50 & 2268 & 2269.15 & 3.15 & 81.47 & 9.87 & 5.50 \\
\hline $32811.006^{\mathrm{B}}$ & - & $11 / 2$ & 0.01 & 45.34 & 24.01 & 30.63 & 1493 & 1493.475 & 0.01 & 45.34 & 24.01 & 30.63 \\
\hline 32896.371 & $4 f^{12} 6 p ?$ & $9 / 2$ & 0.41 & 54.03 & 26.06 & 19.50 & 1639 & 1645.89 & 0.41 & 54.03 & 26.06 & 19.50 \\
\hline 33028.394 & - & $9 / 2$ & 1.03 & 57.60 & 29.03 & 12.35 & 1711 & 1729.536 & 1.03 & 57.60 & 29.03 & 12.35 \\
\hline 33565.895 & - & $9 / 2$ & 0.09 & 81.79 & 11.79 & 6.33 & 2093 & 2093.445 & 0.09 & 81.79 & 11.79 & 6.33 \\
\hline 33988.301 & - & $11 / 2$ & 2.47 & 59.18 & 22.01 & 16.33 & 1854 & 1854.205 & 2.47 & 59.18 & 22.01 & 16.33 \\
\hline 34196.355 & - & $9 / 2$ & 23.25 & 15.36 & 14.76 & 46.62 & 2382 & 2387.91 & 23.25 & 15.36 & 14.76 & 46.62 \\
\hline 34341.611 & - & $11 / 2$ & 0.11 & 77.15 & 13.14 & 9.60 & 1990 & 2019.30 & 0.11 & 77.15 & 13.14 & 9.60 \\
\hline 34563.257 & - & $11 / 2$ & 0.19 & 4.65 & 6.92 & 88.25 & 905 & 915.785 & 0.19 & 4.65 & 6.92 & 88.25 \\
\hline 36738.247 & - & $7 / 2$ & 0.12 & 29.61 & 43.32 & 26.95 & 1208 & 1207.555 & 0.12 & 29.61 & 43.32 & 26.95 \\
\hline 39277.605 & - & $7 / 2$ & 0.50 & 77.96 & 15.44 & 6.10 & 2048 & 2048.53 & 0.50 & 77.96 & 15.44 & 6.10 \\
\hline 39447.909 & - & $5 / 2$ & 3.76 & 50.43 & 28.89 & 16.92 & 1775 & 1775.62 & 3.76 & 50.43 & 28.89 & 16.92 \\
\hline
\end{tabular}

\subsubsection{Odd Parity Energy Levels and Their Configuration Mixing}

All the 63 odd levels involved in the present experiment have configuration mixing of the type $\left(4 \mathrm{f}^{11} 6 \mathrm{~s}^{2}+4 \mathrm{f}^{11} 5 \mathrm{~d} 6 \mathrm{~s}+4 \mathrm{f}^{12} 6 \mathrm{p}+4 \mathrm{f}^{11} 5 \mathrm{~d}^{2}\right) \quad[6]$. A multiplet ${ }^{4} \mathrm{I}^{0}$ consisted of 3 low odd levels of $4 \mathrm{f}^{11} 6 \mathrm{~s}^{2}$ configuration lying at $6824 \mathrm{~cm}^{-1}, 13338 \mathrm{~cm}^{-1}$ and $16948 \mathrm{~cm}^{-1}$ [1] listed in Table 5 exhibit LIS 6430, 6376 and $5896 \mathrm{MHz}$ and thus confirmed having dominant $96 \% 4 \mathrm{f}^{11} 6 \mathrm{~s}^{2}$ configuration as quoted in the reference [6].11 levels of $4 \mathrm{f}^{11} 5 \mathrm{~d} 6 \mathrm{~s}$ configuration lying at $11309-20319 \mathrm{~cm}^{-1}$ and one level at $22859 \mathrm{~cm}^{-1}$ tentatively assigned to $4 \mathrm{f}^{11} 5 \mathrm{~d} 6 \mathrm{~s}$ configuration [1] have been confirmed on the basis of LIS value $\sim 2400 \mathrm{MHz}$. The LIS $1071 \mathrm{MHz}$ observed in the level at $29011 \mathrm{~cm}^{-1}$ confirms the tentative $4 \mathrm{f}^{12} 6 \mathrm{P}$ configuration. The 4 levels falling at 26098, 29492, 30894 , and $32896 \mathrm{~cm}^{-1}$ were previously assigned tentatively to $4 \mathrm{f}^{12} 6 \mathrm{p}$ configuration [1] exhibit LIS $1595,2089,1781$ and $1639 \mathrm{MHz}$ respectively and found belonging to the dominant $4 \mathrm{f}^{11} 5 \mathrm{~d} 6 \mathrm{~s}$ configuration [6]. 7 unassigned levels falling between 23973- $34563 \mathrm{~cm}^{-1}$ listed in Table 5 can be assigned to dominant $4 \mathrm{f}^{11} 5 \mathrm{~d}^{2}$ configuration. 24 unassigned levels including the level at $32811.008 \mathrm{~cm}^{-1}$ (in reference [6] it was revised to $32810.980 \mathrm{~cm}^{-1}$ ) falling in the energy range of 20517- $39447 \mathrm{~cm}^{-1}$ [1] have average LIS $2000 \mathrm{MHz}$ suggests that these levels should belong to the dominant $4 \mathrm{f}^{11} 5 \mathrm{~d} 6 \mathrm{~s}$ configuration [6].

\section{Conclusion}

The high resolution Er II spectra recorded using the mixture of highly enriched ${ }^{166} \mathrm{Er}$ and ${ }^{170} \mathrm{Er}$ isotopes (7:10 ratio) in the liquid nitrogen cooled HCL. This first detailed investigation of IS, $\Delta \sigma^{166,170}$ in the 85 spectral lines of $\mathrm{Er}^{+}$ were conducted using a FTS. The measurements have contributed significantly to the acquaintance of the known even and odd energy levels of $\mathrm{Er}^{+}$. The main features of this work could be summarized as, the present IS data in 85 lines has enabled us to evaluate LIS, $\Delta \mathrm{T}^{166,170}$ values for 29 even and 63 odd parity energy levels for the first time. The theoretically predicted configuration mixings found in the excellent agreement with the experimentally derived mixings. 4 odd levels tentatively assigned to $4 \mathrm{f}^{12} 6 \mathrm{p}$ configuration were revised to $4 \mathrm{f}^{11} 5 \mathrm{~d} 6 \mathrm{~s}$ configuration. 7 unassigned levels assigned to dominant $4 \mathrm{f}^{11} 5 \mathrm{~d}^{2}$ 
configuration. 9 even levels of $4 f^{11} 6 s 6 p$ and 19 odd levels of $4 \mathrm{f}^{11} 5 \mathrm{~d} 6 \mathrm{~s}$ configuration were confirmed whereas 24 unassigned odd levels designated dominantly to the $4 \mathrm{f}^{11} 5 \mathrm{~d} 6 \mathrm{~s}$ configuration.

\section{References}

[1] W. C. Martin, R. Zalubas, and L. Hagan, "Atomic Energy Levels: The Rare Earth Elements," NSRDS- NBS 60 Washington: National Bureau of Standards, 1978.

[2] T. A. M. van Kleef and J. J. A. Koot, Unpublished material, 1975.

[3] J. Sugar and J. Reader, "Ionization energies of the singly ionized rare earths”, J. Opt. Soc. Am., Vol. 55, pp. 1286, 1965.

[4] S. M. Bentzen, U. Nielsen, O. Poulsen, "Lifetime measurements in singly ionized erbium using fast-beam lasermodulation spectroscopy" J. Opt. Soc. Am. vol. 72, pp. 1210, 1982.

[5] J. E. Lawler, C. Sneden, J. J. Cowan, J-F Wyart, I. I. Ivans, J. S. Sobeck, M. H. Stockett, E. A. D. Hartog, "Improved laboratory transition probabilities for Er II and application to the erbium abundances of the sun and five r- process-rich, metal-poor stars", Astrophys. J., Supp. Ser., vol. 178 pp. 71, 2008.

[6] J-F. Wyart and J. E. Lawler, "Theoretical interpretation and new energy levels in Er II", Phys. Scr., vol. 79, pp. 045301, 2009.

[7] U. Nielsen, K. T. Cheng, H. Ludvigsen, J. N. Xiao, "Hyperfine structure of $4 \mathrm{f}^{12} 6 \mathrm{~s}$ and $4 \mathrm{f}^{12} 5 \mathrm{~d}$ configurations in
${ }^{167} \mathrm{Er}$ II measured by collinear fast-beam laser and radiofrequency laser double-resonance spectroscopy", Phys. Scr. vol. 34, pp. 776, 1986.

[8] L. Wilets and L. C. Bradley, "Isotope shifts in Erbium" Phys. Rev. vol. 87, pp. 1018, 1952.

[9] W. F. Meggers, C. H. Corliss, and B. F. Scribner, "Tables of spectral line intensities”, vol.145 NBS, Washington, 1975.

[10] N. Spector and S. Held, "The first spectrum of erbiumdescription and classification" Report No: IA - 13554-T: Israel Atomic Energy Commission, 1980.

[11] J. Čajko, and R. Textoris, "Determination of the intrinsic quadrupole moment of $\mathrm{Er}^{162}$ from a photoelectric measurement of the isotope shifts of the Er I and Er II lines", Czech J. Phys. B. vol. 17. pp. 917, 1967.

[12] J. Pacheva, "Summaries of the second EGAS- Conference" Hannover, 70 ISV, Fiz. Inst. Bulgar. Acad. Nauk, vol. 21 pp. 41, 1970.

[13] H. D. Kronfeldt and G. Sinn, "Crossed-second-order effects of the isotope shift in the Er II ground configuration $4 \mathrm{f}^{12} 6 \mathrm{~s}$ ", Z. Phys. D, 14 pp. 205, 1989.

[14] B. K. Ankush and M. N. Deo, "Isotope shift measurements in the 660 spectral lines of Er I covering the 340-605 nm wavelength region with a Fourier Transform Spectrometer", JQSRT, vol. 155 pp. 96. 2015.

[15] W. H. King, "Isotope shifts in Atomic Spectra", New York Plenum Press, 1984.

[16] M. Wilson, "Ab initio calculation of core relaxation and screening effects on $|\psi(0)|^{2}$ for Sm and Eu", J. Phys. B, vol. 52, pp. 18, 1972. 